\title{
EMERGENT LITERACY AND LANGUAGE SUPPORT FOR ECD CHILDREN FROM UNDERSERVED COMMUNITIES IN GAUTENG, SOUTH AFRICA: A COLLABORATIVE APPROACH
}

\author{
Stephanie E. Carolus \& Sharon Moonsamy
}

University of the Witwatersrand

South Africa's history of inequality and injustice has influenced its diverse population, who continue to experience marginalisation despite the era of democracy. These underserved communities have little access to services that support their children's language and literacy development. The researchers argue that early intervention supports language and literacy skills of children in early childhood development centres (ECDs), improving literacy acquisition and future scholastic progress. This paper demonstrates that a collaborative approach in ECD interventions influences children's language and literacy skills, and supports their learning. The aim of the study was to establish the levels of emergent literacy and language skills of the children pre- and post-teacher intervention. An exploratory quantitative and qualitative approach was employed with 20 participants from two ECD facilities, 10 from a middle socioeconomic (MSE) group and 10 from a lower socioeconomic (LSE) group. An adapted measure on concepts of print was conducted pre- and postintervention. Oral reading and one-on-one reading strategies were presented to the teacher from the LSE ECD. Data analysis included descriptive and inferential statistics, and content analysis. The findings indicate no difference in vocabulary between LSE and MSE groups, despite the MSE group having better resources at their disposal. Furthermore, there was a significant increase in the LSE group's knowledge on print concepts post-intervention. The teacher observed changes in the teaching methods and in the children's literacy, confirming that low-cost short-term programmes and collaborations do influence ECD teaching and learning. The collaborative role of the speech-language therapist should support both parents and teachers of children in ECD contexts.

Keywords: socially disadvantaged communities, early childhood education, emergent literacy, language development, early intervention, collaboration, teacher instruction, speechlanguage therapist

\section{INTRODUCTION}

South Africa's level of literacy is concerning, as has been expressed repeatedly by researchers as well as those in education and communities (EWN, 2017). The Progress in International Reading Literacy Study (PIRLS) 2011-2016 revealed that 78\% of grade 4s had difficulty in reading. The main contributing factors to delayed literacy development are poverty, displacement and marginalisation, especially in socially disadvantaged communities (SDCs) (Graven, 2013). South Africa has numerous communities that continue to experience social disadvantages even in the post-apartheid era. Fleisch (2008) indicates that over 60\% of South African children experience poverty. These children, who lack stimulation, are at risk with regard to language and literacy development. SDCs have limited access to facilities and resources to promote language and literacy in their young children. Introduction to quality 
literate environments in the early years forms a foundation for successful literacy acquisition (Van Staden \& Bosker, 2014).

It is through early language development that a child acquires the necessary phonological sensitivity to prepare for early literacy skills (Dickinson, McCabe, Anastasopoulos, PeisnerFeinberg \& Poe, 2003). Absence of appropriate early language stimulation will result in deficits with phonological sensitivity and print awareness, posing a threat to the future success of literacy development and ultimately scholastic learning (Dickinson et al., 2003). Thus, early intervention and support programmes for teachers and parents in ECD contexts are avenues that speech-language therapists (SLTs) can be involved in, based on their professional training in language, cognitive development and literacy acquisition.

Limited research, however, has been published on the collaborative roles of SLTs and ECD teachers in underserved populations in South Africa. Some studies conducted locally have examined phonological awareness only, but not concepts of print. This indicates that, in a developing country such as South Africa where SLT services are a scarce-skills profession, there is a growing need to address research-related questions regarding collaborations, language and print concepts within the ECD context. Furthermore, it is important to address the educational and literacy challenges experienced in the South African context, which impact on scholarly success and learning, supporting the rationale for the current study.

The purpose of the study was to demonstrate that the collaboration of SLTs with ECD teachers, influence teaching and learning. The authors argue that explicit teacher instruction will impact the language and literacy performance of the children, despite their socioeconomic status.

\section{THEORETICAL FRAMEWORK}

Constructivist and mediational theories underpinned the study. Vygotsky's theory on the zone of proximal development (ZPD) and Feuerstein's theory of structural cognitive modifiability created the frameworks for the intervention, where a more knowledgeable person (e.g. teacher) scaffolds information for learning (Tzuriel, 2013). This taps into the potential of the children. In this study, the teacher's skills were enhanced through the intervention, with a transition from experienced supervision and guidance to independent completion of literacy tasks with minimal guidance. Adult learning theory was also considered. The teacher as the primary interventionist supported the children's language and literacy development. Feuerstein's criteria for mediated learning (MLE) ensured quality mediation (Tzuriel, 2013). The constructivist framework provided a basis for the intervention, where the teacher created active and engaging learning spaces for the children.

\section{LITERATURE REVIEW}

Children from SDCs are at risk for delay in language and literacy acquisition, which in turn will have a major impact on their future scholastic progress (Nel, Mohangi, Krog \& Stephens, 2016). Access to support services is frequently absent; thus, language and literacy skills are compromised (Moonsamy \& Carolus, 2019). Consequently, a vicious cycle of poor education, unemployment and poverty continues (Nel et al., 2016). South Africa's current literacy levels are reported to be lower than those of many countries in Africa (EWN, 2017). Lower literacy levels may be due to the country's recent past of unequal education and social injustice. Political, social and cultural practices within the home environment as well as in social 
contexts influence literacy acquisition (Bloch, 2002). The variables, including emergent literacy skills, home and ECD environments, and collaborative curricula that impact literacy acquisition and development in young children, are discussed next.

\section{Emergent literacy and language skills}

According to ASHA (2006), emergent literacy refers to the necessary skills learned from birth to preschool, forming the foundational skills needed for later reading and writing. Emergent literacy considers how children interact with print in everyday situations. Activities such as book-sharing, looking at pictures or reading a book, and exposure to a variety of print in the environment afford the child an opportunity to develop skills in recognising rhyming patterns or to identify the shapes of letters and associate print with meaning. With the integration of these experiences, children learn how to combine their expressive language skills and their listening skills with the knowledge they have acquired about print to prepare them for the reading and writing learning processes (ASHA, 2006). This exposure to literate environments seems ideal and is expected to occur in all home contexts; however, in SDCs in South Africa, such resources may be limited or even absent.

\section{Language and literacy in the home context}

The home context forms the first safe environment where young children are exposed to learning opportunities. However, stimulating language and emergent literacy skills may not always be prioritised in SDC populations, as families may have several major challenges because of social challenges. These factors are referred to as proximal risk factors, and include absent environmental opportunities related to low levels of education, lack of parental or caregiver knowledge on the importance of language and literacy development, poverty, unemployment, trauma, and violence (Brittnacher, 2014). Hence, it is necessary for SLTs to collaborate with parents and teachers to support learning in the early years. Early intervention needs to be an inclusive process, as language and literacy acquisition is dependent on relationships between children, parents and significant others (Owens, 2014). According to Owens (2014), successful intervention needs to be family-centred. Taylor, Clayton and Rowley (2004) indicate that families are effective in influencing children's learning; thus, SLTs and teachers should work in collaboration with them. In cases where families are not readily available, SLTs can work with teachers in ECD centres. The SLTs' services support and empower families and teachers in their interaction with children, enhancing the child's opportunities to learn.

\section{Early childhood development contexts}

According to Bloch (2000), literacy learning in multilingual contexts for the majority of South African children is thought to commence only once the child has entered primary school. This confirms that early exposure to reading and writing in underserved populations has not been prioritised. Furthermore, due to cost implications, many children from SDCs may not have had access to ECD facilities. Therefore, it can be deduced that the early stage of literacy development may be limited. Following the PIRLS 2011-2016 assessment, the government has called for a refocus on ECD, as the foundations for successful literacy begin in the early stages. Although this was indicated in White Paper 5, where the benefits of early education were propositioned (DBE, 2011), implementation has been limited. Thus, research into this space is essential so that collaborative support between SLTs and ECD teachers can be understood. In addition, given the multilingual and multicultural landscape of the children 
attending ECDs in South Africa, relevant measures of assessment, intervention and curriculum need to be considered.

\section{Collaborative approaches of SLTs and teachers at ECD centres}

SLT services in South Africa are limited to hospitals and special schools. In addition, few SLTs graduate annually; thus, it is referred to as a scarce-skills profession (Moonsamy, Mupawose, Seedat, Mophosho \& Pillay, 2017). Furthermore, SLTs face the challenge of not having access to cultural and linguistically relevant measures to assess children in South Africa. As families are embedded within a wider cultural context (Owens, 2014), sensitivity to a community's culture is key to enhance learning. Furthermore, the assessment tools and intervention materials need to be relevant and meaningful to the individual. South Africa faces several challenges in this respect, as culturally and linguistically relevant materials are lacking (Southwood \& Van Dulm, 2015). Tasks are thus expected to be adapted to suit the South African population, and responses need to be interpreted with caution to avoid incorrect diagnoses. Thus, studies such as Tayob and Moonsamy (2018) and Moonsamy and Carolus (2019) are necessary, so that new avenues for assessment and intervention material can be explored. SLTs as agents of change have to be creative when working with children from SDCs and will not always be able to do individual interventions. Collaborative service delivery models are thus essential so that systems of support are provided (Moonsamy, 2015). Furthermore, by empowering ECD teachers, SLTs are able to reach more children and provide an integrated service relevant to the context.

From the above discussion, it is evident that all children require effective stimulation in a literate-enriched environment, be it the home or ECD centres. Furthermore, appropriate curricula need to be utilised to ensure contextually relevant learning. The following two research questions guided this enquiry: Is there a difference in the children's knowledge of print concepts and language skills following an ECD teacher intervention within underserved communities in Gauteng? Do the children from the low-income group perform differently on print concepts and language skills to the children from the middle-income group?

\section{RESEARCH METHODOLOGY}

The following objectives operationalised the study's aim:

- To establish whether there are differences in the knowledge base on concepts of print in children who attend ECD facilities in low- (ECD 1 - experimental group) and middle-income (ECD 2 - comparison group) groups within underserved populations in Gauteng pre- and post-intervention.

- To present an intervention to the low socioeconomic (experimental group) ECD 1 facility.

- To establish whether there are differences in the knowledge base of concepts of print of the children in the lower socioeconomic (experimental) group pre- and postintervention.

- To determine the ECD teacher's perception and experiences on emergent literacy in the experimental group school. 


\section{Research design}

A comparative pre- and post-test intervention, non-experimental design was used. Quantitative and qualitative research approaches were employed. Triangulation of data sources from the children and teachers, and the exit interview contributed to the validation and credibility of the data obtained.

\section{Participants}

A convenient non-probability sampling strategy was used for the study. Non-probability sampling ensured that no random selection was involved in the sampling of participants (Kothari, 2004). Twenty children, aged four to five, who attended ECD facilities within the area of Westbury were assessed using an adapted version of the Marie-Clay Literacy Assessment. A total of 10 participants, five females and five males, was selected from each of two ECD facilities. The mean age of the children for ECD 1 was five years and one month. The mean age of the children for ECD 2 was four years and seven months. It was noted that the first language spoken and the language of learning and teaching was English for all participants included in the research study (Figure 1).

\section{Inclusion and exclusion criteria}

Both males and females were included in the study as this represented the demographics of the group. Children were required to be four to five years old, as they are developing print awareness before formal reading instruction at this age (Justice \& Ezell, 2001). Children who attended the ECD facilities and did not fall within the Social Development Unit (SDU) of Westbury's criteria of an underserved population were excluded. Children with a communication and/or learning disorder were referred to the clinic for diagnostic speech therapy, educational psychology or audiology services, depending on the disorder. Children with a disability, such as a learning difficulty or a speech and language delay, were not included in the study as the study focused on emergent literacy skills of typically developing children. This ensured that no skewness of the results occurred due to outliers, and that the participants selected were a small representation of typically developing children in the lower and middle socioeconomic classes of the Westbury area.

It was important for the ages of the participants to be equally distributed to ensure that the participants fell within the inclusion criteria of the study. All participants were within the age range of four years to 5.6 years (Average age $=$ four years and nine months), as indicated in Figure 1. 


\section{Demographics of participants}

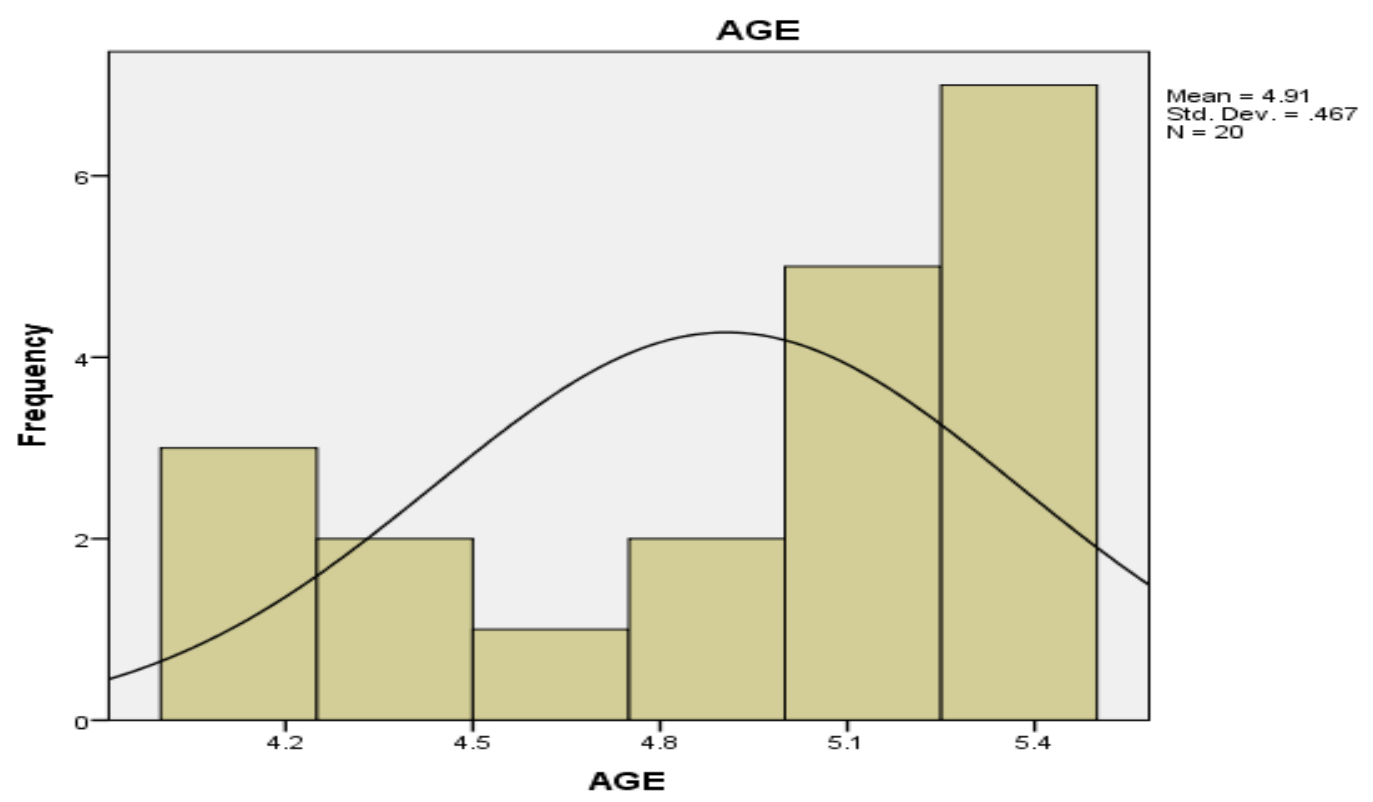

Figure 1: The distribution of participant ages at the time of assessment completion

The home language or L1 of all the participants was reported as English, and the majority of the participants spoke Afrikaans as their second language or L2. English was the language of learning and teaching (LOLT) at the schools. For the purpose of the assessment, English was used as the language of assessment. The teacher interviewed from ECD 1 also made use of English, with no other languages spoken in class. ECD 1 received the intervention programme as part of the study.

\section{Research process}

Ethical clearance was obtained from the Social Development Programme coordinators and the University of Witwatersrand Human Research and Ethics Committee (Non-medical) protocol number: STA_2017_03. Following ethical clearance, a pilot study was conducted with two children to ensure that the time, questions and instructions were suitable for the ECD contexts. These two children did not form part of the 20 participants in the main research study. The main study required each child from ECD 1 and ECD 2 to complete three 20- to 30-minute assessments. An intervention was then conducted at ECD 1. ECD 2 did not receive the intervention during the study and continued with their own programme. After the fourweek intervention at ECD 1, re-assessments were conducted at both ECD centres and the results of each ECD facility were analysed and compared. Once all the assessments were completed, an exit interview, using open-ended questions, was conducted with the teacher from ECD 1.

\section{Data collection and analysis}

Open-ended questions were used to elicit responses from the participants during their assessments and from the teacher during the exit interview (questions are available from the authors). All assessments and interviews were audio recorded and transcribed. Results were tabulated and arranged for data analysis to allow for the cross-checking of results. Multivariate data analysis and multi-factor tools such as frequency distribution tables and 
graphs were used as the study involved many variables. The pre- and post-intervention assessment results were then compared between the two ECD facilities to identify the extent of any progress made in their emergent literacy skills. Additionally, within-group comparisons of pre- and post-test performance were conducted for ECD 1. Member checking ensured that all data recorded were accurate. Content analysis was applied in examining and describing the common patterns identified in the exit interview responses (Braun \& Clarke, 2006).

\section{Description of the context}

The research sites were two ECD facilities situated in the area of Westbury, Johannesburg. One facility was from the lower socioeconomic area. This formed ECD 1 (experimental school - intervention group). The second ECD (ECD 2 - comparison group) was from the middle socioeconomic group. The socioeconomic status was determined by the SDU of the Westbury area. The community of Westbury is a diverse and multilingual society. The range of ECD facilities varied. Some facilities were able to function with minimal support from the SDU, while other ECD facilities required maximum assistance and support to ensure that adequate stimulation was provided for the children attending the ECD facilities.

\section{Instruments}

The following measurements were use in the study.

\section{Marie Clay Concept about Print Assessment}

An adapted version of Marie-Clay's (2000) Concept about Print Assessment was administered. The assessment was conducted twice: pre- and post-intervention.

Early Childhood Learning Assessment System

ECLAS-II (Early Childhood Learning Assessment System - 2nd edition): literacy development checklist was used as a guideline to develop the intervention programme.

\section{Receptive and expressive one-word picture vocabulary assessments}

Receptive and expressive one-word picture vocabulary assessments were used to determine the children's receptive and expressive vocabulary levels.

\section{Exit interview survey}

The exit interview included open-ended questions, which allowed the participant (teacher) an opportunity to describe her ideas, opinions, thoughts and experiences on reading and writing within the ECD facilities (Silverman, 2011). The exit interview included the following key areas: emergent literacy curriculum-based programmes; qualifications of ECD facilitators; ECD facility resources and materials; value of emergent literacy; and strategies used to facilitate emergent literacy development. 


\section{Audio recording}

The speech-language samples from the participants and the exit interview were recorded, transcribed and transferred onto a password-protected computer to ensure the confidentiality of all data obtained.

\section{Intervention programme}

The intervention programme was adapted from the ECLAS-II guidelines stipulated by the New York City Department of Education (Klein, 2006). The intervention training programme was conducted with ECD 1 on one day, after the initial assessments. The intervention programme was designed for one week, and was then repeated for three more weeks using different book materials each week. For example, the teacher was asked to let the children choose one book every week and focus on that book for the first week, but to change the book for the following week. Vygotsky's ZPD and sociocultural theory were foundational so that the children learnt how to complete a task independently after completing the same task under experienced supervision and guidance (Chaiklin, 2003). Thus, the programme was designed to target literacy activities under direct teacher supervision, after which the children explored, discovered and interacted with books and literacy activities independently or with partners in the classroom. Once the intervention programme had been completed, the children were reassessed to determine whether any progress in literacy skills had occurred. ECD 2 continued with their regular programme. For ethical reasons, the researchers provided the intervention to the ECD 2 facility once all data for the study had been obtained. The intervention and its impact on the ECD 2 group were not for research purposes (programme details available from the authors).

\section{Data analysis}

Quantitative and qualitative data were analysed using descriptive and inferential statistics, and content analysis. Paired sample t-tests were conducted to establish the present changes in the scores obtained from the participants. Prior to concluding the level of influence the intervention may have had, each aspect of the assessment scores was studied and analysed individually. Each of the measures is explained under its related headings and in conjunction with the objectives of the study. The themes identified in the study are discussed, and visual representations and quotes support the presentation.

\section{Rigour, validity and reliability}

The study made use of research tools that were appropriate for the research, such as an adapted observation checklist for print awareness and audio recordings of the children's vocabulary productions, to ensure the rigour, validity and reliability of the study. All results were cross-checked by the researchers to ensure that the results correlated with the observations made during the assessments. All ethical parameters were maintained. Verbal and written permission was obtained from the parents of the children, the teachers and principals of the ECD centres and the SDU. Assent from the participating children, using their thumbprints, was obtained prior to the commencement of the study. To maintain anonymity, no identifying information was reported. 


\section{RESULTS}

The results are presented in line with the study's objectives.

\section{Quantitative data analysis}

The sample size of the study was small, hence non-parametric statistics were used to analyse and compare the assessment results obtained from each ECD facility, as well as the results of each participant. T-tests and paired sample t-tests were conducted for each participant, and then for the group as a whole.

The below key codes are used in the tables and figures that follow.

\begin{tabular}{|l|l|}
\hline ECD1 & Experimental group - literacy intervention group - LSE \\
\hline ECD 2 & Comparison group - MSE \\
\hline Frequency & Number of participants \\
\hline $\mathrm{Ra}(\mathrm{RS})$ & Raw scores, receptive vocabulary - pre-test \\
\hline $\mathrm{Rb}(\mathrm{RS}):$ & Raw scores, receptive vocabulary - post-test \\
\hline $\mathrm{Ea}(\mathrm{RS}):$ & Raw scores, expressive vocabulary - pre-test \\
\hline $\mathrm{Eb}(\mathrm{RS}):$ & Raw scores, expressive vocabulary - post-test \\
\hline $\mathrm{RD}(\mathrm{a}):$ & Print concept - pre-test \\
\hline $\mathrm{RD}(\mathrm{b}):$ & Print concept - post-test \\
\hline
\end{tabular}

Comparison of pre- and post-test results of the receptive and expressive vocabulary and print awareness in ECD 1 (intervention group)

Table 1: Sample t-test data analysis of ECD 1

\begin{tabular}{|l|l|l|l|l|l|}
\hline \multicolumn{2}{|l|}{ Paired sample statistics } & Mean & $\mathrm{N}$ & Std. deviation & Std. error mean \\
\hline \multirow{2}{*}{ Pair 1 } & $\mathrm{Ra}(\mathrm{RS})$ & 48.70 & 10 & 11.392 & 3.603 \\
\cline { 2 - 6 } & $\mathrm{Rb}(\mathrm{RS})$ & 66.80 & 10 & 14.665 & 4.638 \\
\hline \multirow{2}{*}{ Pair 2 } & $\mathrm{Ea}(\mathrm{RS})$ & 43.70 & 10 & 7.846 & 2.481 \\
\cline { 2 - 6 } & $\mathrm{Eb}(\mathrm{RS})$ & 49.60 & 10 & 9.046 & 2.860 \\
\hline \multirow{2}{*}{ Pair 3 } & $\mathrm{RD}(\mathrm{a})$ & 5.60 & 10 & 2.011 & 0.636 \\
\cline { 2 - 6 } & $\mathrm{RD}(\mathrm{b})$ & 10.60 & 10 & 2.503 & 0.792 \\
\hline
\end{tabular}

The pre-test results of ECD 1's receptive vocabulary development revealed an average score of 48.70, with a post-test average score of 66.80 (Table 1). These results suggest that the participants' receptive vocabulary development was below the norm when compared to peers of the same age, according to the scoring criteria of the Receptive One-Word Picture Vocabulary Test. The second set of results were the expressive vocabulary assessment scores, which indicated an average score of 43.70 at pre-test and 49.60 at post-test. The participants' expressive vocabulary development was below the norm when compared to peers of the same age, according to the scoring criteria of the Expressive One-Word Picture Vocabulary Test. The third set of results indicated the assessment scores for print concept. ECD 1 obtained an average score of 5.60/15 pre-test and 10.60/15 post-test. Significant progress, however, was noted for the assessment scores for print concept (see Table 2). This may suggest that the intervention provided to ECD 1 might have influenced their performance on the concepts about print. 
Table 2: Paired sample t-test results for ECD 1

\begin{tabular}{|c|c|c|c|c|c|c|c|c|c|c|}
\hline & \multicolumn{5}{|c|}{ Paired differences } & \multirow[t]{3}{*}{$\mathbf{t}$} & \multirow[t]{3}{*}{ df } & \multirow{3}{*}{$\begin{array}{l}\text { Sig. (2) } \\
\text { tailed) }\end{array}$} \\
\hline & & & \multirow[t]{2}{*}{ Mean } & \multirow[t]{2}{*}{$\begin{array}{l}\text { Std. } \\
\text { deviation }\end{array}$} & \multirow[t]{2}{*}{$\begin{array}{l}\text { Std. } \\
\text { error } \\
\text { mean }\end{array}$} & \multicolumn{2}{|c|}{$\begin{array}{l}95 \% \text { confidence } \\
\text { interval of the } \\
\text { difference }\end{array}$} & & & \\
\hline & & & & & & Lower & Upper & & & \\
\hline $\begin{array}{l}\text { Pair } \\
1\end{array}$ & $\begin{array}{l}\mathrm{Ra}(\mathrm{RS}) \\
\mathrm{Rb}(\mathrm{RS})\end{array}$ & & -18.100 & 15.423 & 4.877 & -29.133 & -7.067 & -3.711 & 9 & 0.005 \\
\hline $\begin{array}{l}\text { Pair } \\
2\end{array}$ & $\begin{array}{l}\mathrm{Ea}(\mathrm{RS}) \\
\mathrm{Eb}(\mathrm{RS})\end{array}$ & - & -5.900 & 5.666 & 1.792 & -9.953 & -1.847 & -3.293 & 9 & 0.009 \\
\hline $\begin{array}{l}\text { Pair } \\
3\end{array}$ & $\begin{array}{l}\mathrm{RD}(\mathrm{a}) \\
\mathrm{RD}(\mathrm{b})\end{array}$ & - & -5.000 & 2.539 & .803 & -6.816 & -3.184 & -6.228 & 9 & 0.000 \\
\hline
\end{tabular}

Comparison of pre-and post-test results of the receptive and expressive vocabulary and print awareness in ECD 2 (comparison group)

Table 3: Sample t-test data ECD 2

Paired sample statistics

\begin{tabular}{|l|l|l|l|l|l|}
\hline \multicolumn{2}{|c|}{} & Mean & $\mathrm{N}$ & Std. deviation & Std. error mean \\
\hline \multirow{2}{*}{ Pair 1 } & $\mathrm{Ra}(\mathrm{RS})$ & 43.30 & 10 & 22.588 & 7.143 \\
\cline { 2 - 6 } & $\mathrm{Rb}(\mathrm{RS})$ & 69.30 & 10 & 15.254 & 4.824 \\
\hline Pair 2 & $\mathrm{Ea}(\mathrm{RS})$ & 38.50 & 10 & 14.081 & 4.453 \\
\cline { 2 - 6 } & $\mathrm{Eb}(\mathrm{RS})$ & 46.70 & 10 & 9.753 & 3.084 \\
\hline \multirow{2}{*}{ Pair 3 } & $\mathrm{RD}(\mathrm{a})$ & 6.90 & 10 & 1.524 & 0.482 \\
\cline { 2 - 6 } & $\mathrm{RD}(\mathrm{b})$ & 7.70 & 10 & 2.003 & 0.633 \\
\hline
\end{tabular}

The results indicate that the participants from ECD 2 obtained a pre-test average score of 43.30 and a post-test score of 69.30 for the receptive vocabulary assessment (Table 3 ). These scores were below average when compared to peers of the same age, according to the criteria of the Receptive One-Word Picture Vocabulary Test. The second set of results reflected the expressive vocabulary abilities of the ECD 2 participants. The results indicate a pre-test average score of 38.5 and a post-test score of 46.70, which indicates that the groups' expressive vocabulary scores were below average when compared to peers of the same age, according to the criteria of the Expressive One-Word Picture Vocabulary Test. The third set of results examined the participants' knowledge of print concepts, reflecting assessment scores of 6.90/15 pre-test and 7.70/15 post-test. Although increased performance was noted for print concepts, the progress was minimal and not statistically significant, as highlighted in Table 4. 
Table 4: Paired sample t-test results for ECD 2

\begin{tabular}{|c|c|c|c|c|c|c|c|c|c|}
\hline & \multicolumn{5}{|c|}{ Paired differences } & \multirow[t]{3}{*}{$\mathbf{t}$} & \multirow[t]{3}{*}{ df } & \multirow{3}{*}{$\begin{array}{l}\text { Sig. (2- } \\
\text { tailed) }\end{array}$} \\
\hline & & \multirow[t]{2}{*}{ Mean } & \multirow[t]{2}{*}{$\begin{array}{l}\text { Std. } \\
\text { deviation }\end{array}$} & \multirow[t]{2}{*}{$\begin{array}{l}\text { Std. } \\
\text { error } \\
\text { mean }\end{array}$} & $\begin{array}{l}95 \% \\
\text { interval } \\
\text { differen }\end{array}$ & $\begin{array}{l}\text { onfidence } \\
\text { of the }\end{array}$ & & & \\
\hline & & & & & Lower & Upper & & & \\
\hline $\begin{array}{l}\text { Pair } \\
1\end{array}$ & $\begin{array}{l}\mathrm{Ra}(\mathrm{RS}) \\
- \\
\mathrm{Rb}(\mathrm{RS})\end{array}$ & -26.000 & 17.751 & 5.613 & -38.699 & -13.301 & -4.632 & 9 & 0.001 \\
\hline $\begin{array}{l}\text { Pair } \\
2\end{array}$ & $\begin{array}{l}\mathrm{Ea}(\mathrm{RS}) \\
- \\
\mathrm{Eb}(\mathrm{RS})\end{array}$ & -8.200 & 9.796 & 3.098 & -15.207 & -1.193 & -2.647 & 9 & 0.027 \\
\hline $\begin{array}{l}\text { Pair } \\
3\end{array}$ & $\begin{array}{l}\mathrm{RD}(\mathrm{a}) \\
\mathrm{RD}(\mathrm{b})\end{array}$ & -0.800 & 1.229 & 0.389 & -1.679 & 0.079 & -2.058 & 9 & 0.070 \\
\hline
\end{tabular}

Comparison of pre- and post-test results for receptive vocabulary, expressive vocabulary and print awareness between ECD 1 (intervention group) and ECD 2 (comparison group)

When comparing the receptive vocabulary, expressive vocabulary and knowledge of print concepts results between the two ECD facilities, the following findings were noted:

Both ECD facilities presented with significant differences in receptive and expressive vocabulary development pre- and post-test. The difference between the scores obtained indicated that both ECD participant groups were developing receptive and expressive vocabularies similarly, despite the difference in socioeconomic status. When analysing the resources and materials of each ECD facility, it was found that there were no changes made to the type or number of resources at pre-test or at post-test. This may suggest that the resources and materials may not have had a significant impact on the development of receptive and expressive vocabulary for both ECD participant groups. Nevertheless, the results of ECD 1 and ECD 2's receptive and expressive vocabulary were below the norm, as per the test manual. It is important to note, though, that the tests are not standardised on the South African population and need to be interpreted with caution.

The print concept assessment scores did not improve significantly for the participants of ECD 2. Conversely, a significant improvement in the concept about print scores was noted for the participants of ECD 1. Figures 2 and 3 show the pre- and post-test print concepts results for ECD 1 and ECD 2 respectively. 


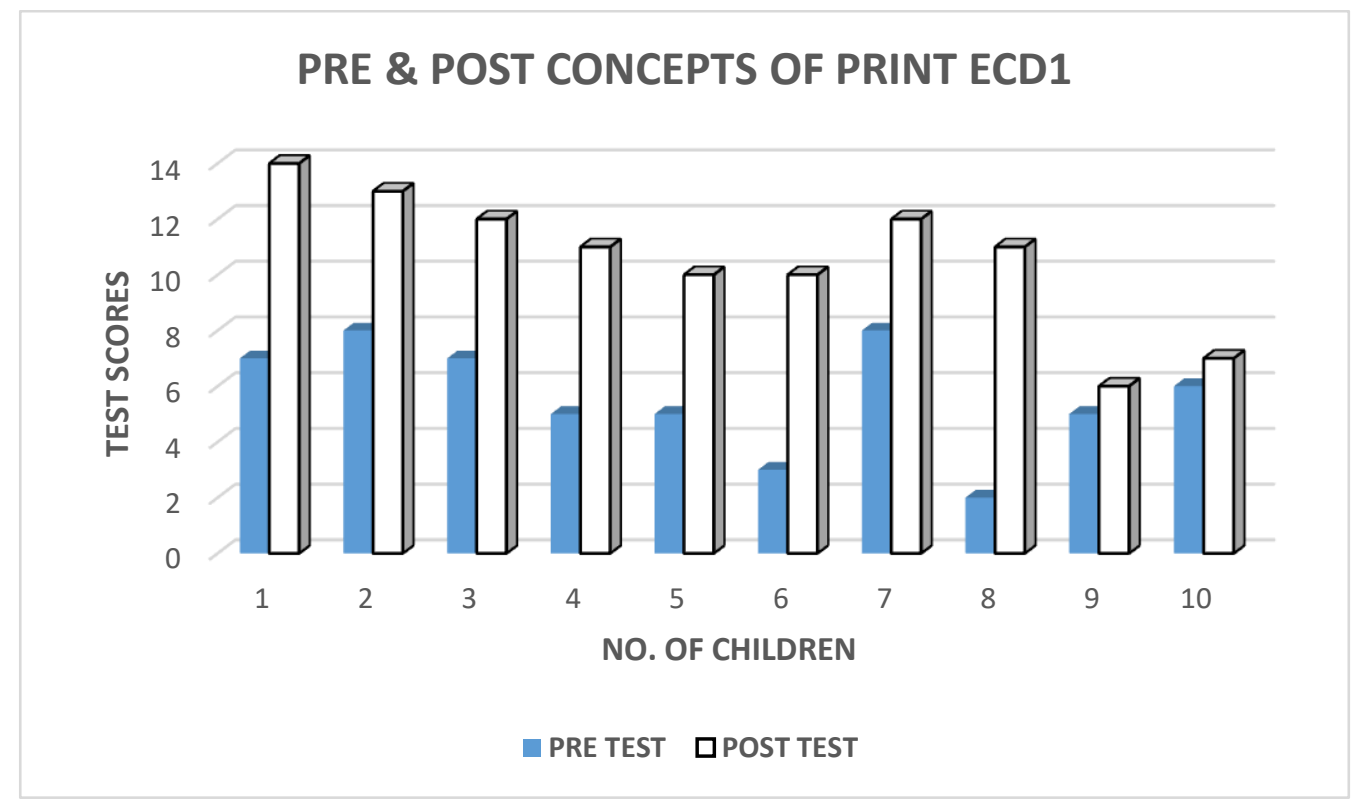

Figure 2: Pre- and post-test scores on print concepts for ECD 1

\section{PRE \& POST CONCEPTS OF PRINT ECD2}

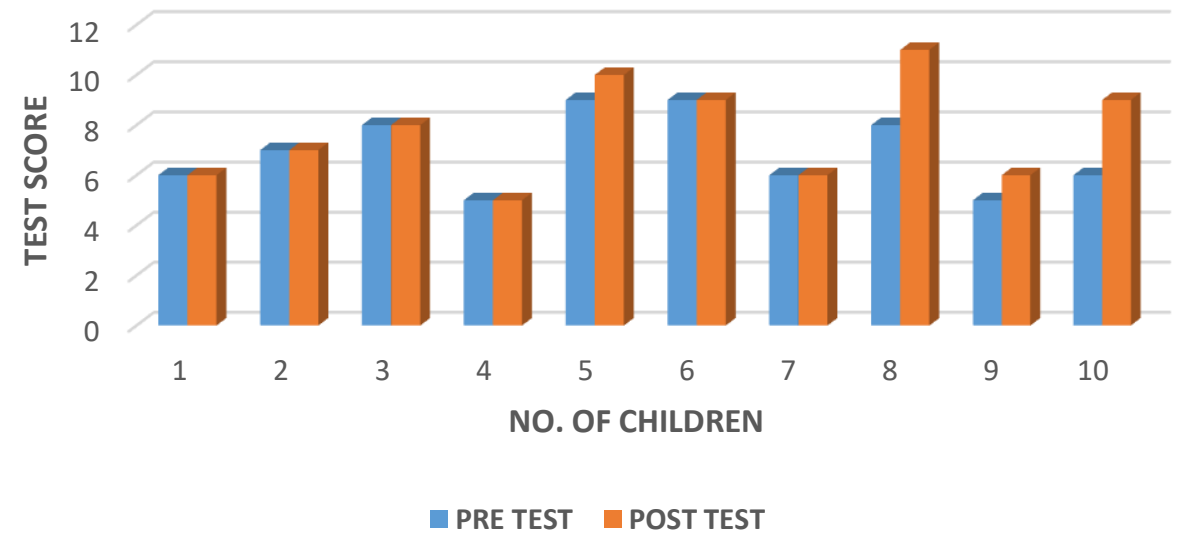

Figure 3: Pre- and post-test scores on print concepts for ECD 2

These results confirm the improved and significant performance of ECD 1 when compared to ECD 2.

\section{Qualitative data analysis}

Qualitative data from the interview with the teacher/facilitator from ECD 1 were analysed. The face-to-face interview included questions that encouraged discussions around the various themes which play a role in the development of concepts of print in children attending ECD facilities in SDCs. The findings are presented below according to themes. 


\section{Emergent literacy curriculum-based programmes}

The interviewee reported that the curriculum followed was stipulated by the DBE (2011). This was expected as most government educational institutions follow the DBE's curriculum. Katims (1991) states that emergent literacy behaviours of young children increase with the implementation of structured emergent literacy curricula and have also proven to be beneficial for young learners with special learning requirements. The school's curriculum provided the researchers with a foundation on which to build new concepts related to the intervention programme. The researchers were also able to note the literacy content that was or was not covered in the curriculum. This ensured that the intervention content was contextually appropriate.

\section{ECD facilitators' qualifications}

Qualifications of the teachers at the ECDs were recorded. This provided the researchers with an understanding of the teachers' content knowledge on ECD. It is important for facilitators to have an adequate knowledge and understanding of the content taught so that relevant content and processes are imparted. ECD 1 had an advantage in that three $(n=5)$ facilitators or teachers either had or were pursuing an ECD level 4 qualification. This was unexpected for a lower socioeconomic ECD facility, as generally most ECD facilities have few to no facilitators with formal qualifications or training. A major challenge faced by many ECD facilities in South Africa is the absence of formal training. The limited formal training may be due to the lack of financial resources to subsidise ECD teachers and facilities (Atmore, 2012). This was clearly noted when the interviewee reported that the courses were expensive and that sourcing funding to send her colleagues for ECD training was difficult.

The data on the teacher qualifications provided further information and insight into understanding the level of facilitation and teaching the children at these ECDs were receiving. The interviewee reported that they did receive partial guidance in educating the facilitators and teachers:

... although I am currently the only teacher here with a qualification, I do what I can to assist and guide the other facilitators to ensure they are giving the children the best possible education we can offer. The Social Development Unit also helps with this process ....

This quote suggests that there was a process to obtaining a qualification and that it was being followed. However, the interviewee made an attempt to share knowledge and skills with facilitators or teachers so that the children would receive good teaching. Hlalele (2012) asserts that this view on education is based on human rights and social justice. Hence, appropriate training and qualifications are necessary for optimal education.

\section{ECD facility's resources and materials}

The intervention facilitator was asked to describe the types of resources used within ECD 1. Human resource development has made ECD development a priority in South Africa (Biersteker \& Dawes, 2008). Financial support is not sufficient for ECD facilities to provide adequate services to the children attending the facility. This often impacts on the quality of teaching and facilitation that the children receive. 
Is there ever enough resources? We buy our own resources using our own pocket money because the parents cannot afford to pay extra fees for stationery. It is also difficult to ask parents to buy stationery as they often buy the cheapest option which is not always the best option for children.

Biersteker and Dawes (2008) report that the most disadvantaged communities tend to have the poorest services. Thus, it was important for the researchers to identify the extent of the lack of resources and materials, and to determine its influence on ECD development. It was reassuring that the ECD 1 facilitator maximised her use of the resources that her school had.

\section{Teacher perceptions on emergent literacy}

The interviewee described her views and opinions on parent involvement in the development of literacy skills in the home environment. Furthermore, she shared her views on the value of literacy development within her own ECD facility. These data provided the basis on which the intervention guidelines were formulated for facilitators. Rhyner (2008) indicates that the value perceived by the teacher will influence the impact an intervention has on the children.

Parent involvement is negligible. Often, we ask parents to read with their children as homework is done and completed which is good. The problem is when the child comes back to day care and they have no clue what is going on. I suspect that parents are completing the homework to get it out of the way and not taking the time to explain and make sure that the child understands what they are doing.

The interviewee's opinion may suggest that, although the parents (in general) may value their children's educational development, their approach may suggest differently. This begs the question of generalisation from the ECD facility to the home setting. Carryover between home and the ECD seems to be insufficient for adequate learning to occur. This is concerning, as Van Staden and Bosker (2014) indicate that reading is a cultural practice that begins at home. Hence, a collaboration between the home and school environment needs to be developed. The interviewee further pointed out that there is a difference in values relating to literacy between the ECD facility and the home environment:

Here we value education and reading. I grew up reading with my parents every night before bed and sometimes during the day. Reading is how the children pick up on language especially grammar but from what I have seen, the parents are just 'too busy' to ensure they spend the little extra time making sure their children fully understand their work.

These perspectives corroborate the view that some parents in SDCs may be prioritising their needs of survival rather than focusing on stimulating the child.

Strategies used to facilitate the development of emergent literacy

The strategies modelled by the researchers enabled the facilitators to make decisions on what strategies they may include or adapt to allow for improved emergent literacy progress and development (Rhyner, 2008). The strategies used are depicted in Figure 4 below. 


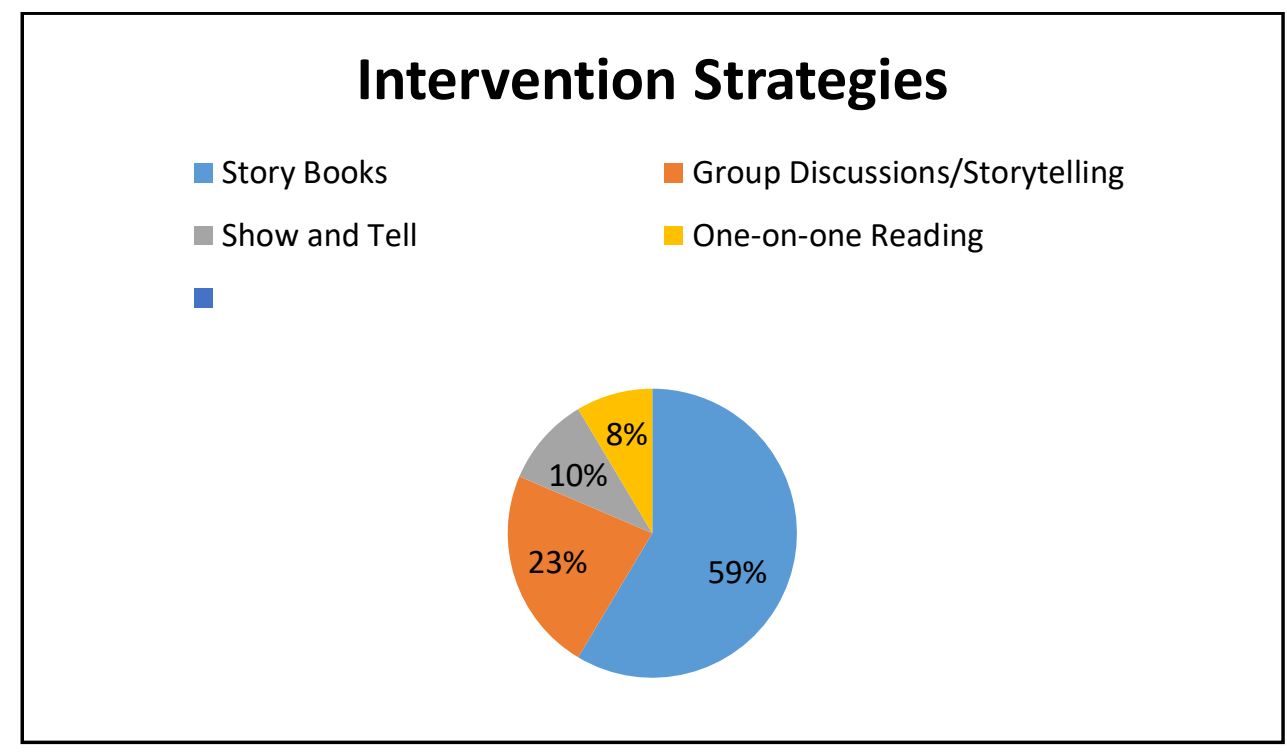

\section{Figure 4: Intervention strategies used in the literacy intervention programme}

The interviewee stated that the intervention strategies provided had made a noticeable difference in the children's use and understanding of books. She proposed that a workshop or reading and writing programme would be beneficial for her and her staff, as she personally found the strategies to be helpful with teaching early reading and writing. From the results in Figure 4, storybook reading seemed to dominate the strategy application.

\section{DISCUSSION}

The main aim of the study was to establish the knowledge of print concepts and language skills in children, aged 4 to 5, attending mid- and low-socioeconomically disadvantaged ECD facilities in underserved communities in Gauteng. Several concepts emerged from the findings from the current study, and these are deliberated below.

Several tensions arise when education in South Africa is discussed, even at ECD level. To redress the past inequalities in education, quality instruction is needed, more so in unserved and marginalised populations. Explicit emergent literacy intervention at ECD facilities is foundational as the development of literacy skills for school-readiness is crucial. Many teachers and facilitators have had little or no training due to their inability to attain formal and epistemological access (Walton, Bekker \& Thompson, 2015), as was evidenced in this study. Furthermore, training is unaffordable for many facilitators from SDCs. Hence, a collaborative framework with SLTs can be adopted to support teacher and parent education.

The impact of socioeconomic status on the development of reading and writing cannot be ignored, as context is foundational to children's learning. In South Africa, the growth in the rate of poverty and its negative effects on the development of literacy are increasing at an alarming rate (Bloch, 2000). This would suggest that, the greater the poverty or the lower the socioeconomic status, the greater the risk for delay in reading and writing skills. Nevertheless, contrary to studies conducted, the current study suggests that there is no significant difference in the development of vocabulary skills between the lower and middle socioeconomic classes. The ECD facilities differed greatly in property space, classroom availability and basic resources such as paper, tables and chairs, but the children in the two groups were developing 
their understanding (receptive) and spoken (expressive) language abilities at similar rates. Both groups' language skills, however, were below the norm of typically developing children. This relates back to the context as well as to the resources applied.

The context of the study needs to be understood within the broader perspective of South Africa's history. Often, socioeconomic status influences parents' involvement in the development of their children. Many parents in SDCs are required to work longer hours and consequently have less time to focus on their children and their education. In the lower and middle socioeconomic groups, parents often report that there is a dire need to have more than one job and more than one breadwinner to cover living expenses. This was brought up in the results, as facilitators often complained that parents were not involved in the education and reading development of their children due to time constraints. A decrease in parent-child engagement through reading activities is detrimental to the development of literacy skills and later scholastic success (Taylor et al., 2004). Busy day-to-day schedules and routines may dampen the appearance of parents' value of reading and writing, or it may decrease their value altogether. The teacher indicated a perceived difference between the ECD facilitators and parent involvement. The main reason for the difference was that the two ECD facilitators focused on educational and literacy development, whereas the parents focused on meeting the basic needs of the family. Hence, the responsibility seems to be placed on the ECD facilitators to aid the development of literacy. A collaborative approach might be the solution towards including parents, ECD teachers and SLTs, drawing on the expertise of all stakeholders.

The home and the ECD contexts are indispensable to early language and literacy acquisition. Print concepts need to be immersed in language instruction that is contextually relevant, so that print is meaningful. Parents and teachers need to promote a literate environment. Even though this may seem difficult in SDCs, collaborative approaches with SLTs can be fostered, as early intervention in the areas of language and literacy are essential for children with limited access to stimulating environments. This study therefore embarked on this project.

The intervention strategies that were implemented at ECD 1 and their impact on the children's literacy performance were interesting, but not surprising, as explicit instruction does change performance in learning. Strategies such as oral reading and one-on-one reading were suggested to the ECD facilitators as means to improve literacy development. Oral reading and storytelling are an important part of the African culture (Miller \& Pennycuff, 2008), making the intervention relevant to the context. Not only does it provide opportunities to develop comprehension skills, but it also allows for the development of expressive language abilities and aids communication of messages through narratives.

When the intervention was introduced to ECD 1, there were minute yet effective changes that were observed in the current teaching methods of developing literacy. The results from the post-test on concepts about print indicated a statistically significant increase in scores for the children, suggesting that the intervention techniques may have contributed towards the development of literacy. When the ECD facilitators reported that they noted a difference in the children's abilities and skills with books and literacy, it further confirmed that small changes to methods may be sufficient to influence literacy development. The current study's findings are supported in the literature, demonstrating that brief inputs can make a difference to the strategies that ECD teachers apply when teaching (McDonald, Proctor, Gill, Heavens, Marr \& Young, 2015). The findings confirm that just having a curriculum is not as powerful as working through the content and reflecting on the process, collaboratively, within the ZPD. 


\section{CONCLUSIONS}

Our argument that explicit teacher instruction impacts the language and literacy performance of children, despite their socioeconomic status, has been supported by the findings from this study. Explicit instruction and literate environments are powerful promoters of literacy, building print awareness, language and cognitive skills. Moreover, a collaborative lens adds to avenues in redressing the low literacy levels in SDCs in South Africa and in any developing context. Collaborative practices (parents, teachers and SLTs) and systemic paradigms are also a way forward in providing meaningful input, making it contextually relevant. Information, workshops and mentoring or support for both teachers in ECDs and parents are thus recommended, as these things empower and build capacity in individuals that are significant in the lives of young children.

The sample size was small and the findings cannot be generalised, but the experiences of the ECD teachers in this SDC contribute to the understanding of explicit instruction in early literacy and language skills. The findings also contribute to understanding the power of collaborations between professions. The duration of the intervention may have been short, but changes in the children's performance and teachers' experiences were observed, supporting studies on the effectiveness of brief interventions (McDonald et al., 2015). In future studies, longer intervention and monitoring time, as well as parent training in book-sharing and emergent literacy in SDCs, would yield much needed data. Furthermore, topics identifying strengths in parent-child and teacher-child interactions, and how these interactions support young children's transition into school, are suggested. This strength-based approach will add a new dimension to this area of research.

\section{REFERENCES}

ASHA. 2006. Let's Talk: For People with Special Communication Needs-Emergent Literacy: Early Reading and Writing Development. Retrieved September 14, 2017, from https://www.asha.org.

ATMORE, E. 2012. Challenges facing the early childhood development sector in South Africa. South African Journal of Childhood Education, 2(1):20.

BIERSTEKER, L \& A DAWES. 2008. Early childhood development. In Kraak, A. \& Press, K. (Eds.) Human Resources Development Review 2008: Education, Employment and skills in South Africa, 185-205. Cape Town: HRSC Press. Pp. 185-205.

BLOCH, C. 2002. A case study of Xhosa and English bi-literacy in the foundation phase versus English as a 'medium of destruction': many languages in education: issues of implementation. Perspectives in Education, 20(1):65-78.

BLOCH, C. 2000. BLOCH, C. 2000. Young children's literacy learning in multilingual contexts with special reference to South Africa. A Paper presented at the Conference on "The Language and Development in Southern Africa-Making the right choices", 11-13 April 2000, Okahandja, Namibia.

BRAUN, V \& V CLARKE. 2006. Using thematic analysis in psychology. Qualitative Research in Psychology, 3(2):77-101.

BRITTNACHER, L. 2014. The role of the personal and contextual factors on emergent literacy skills. PhD thesis. The University of Wisconsin, Milwaukee, WI.

CHAIKLIN, S. 2003. The zone of proximal development in Vygotsky's theory of learning and school instruction. In A. Kozulin, B. Gindis, V.S. Ageyev, \& S. M. Millier (Eds.), Vygotsky's educational theory in cultural context, 1(1), 39-64. Cambridge, Cambridge University Press. 
CLAY, MM. 2000. Concepts about print: what have children learned about the way we print language? Portsmouth, NH: Heinemann.

DEPARTMENT OF EDUCATION. 2011. Universal access to grade R. Policy framework. Pretoria: Department of Education.

DICKENSON, DK, A MCCABE, L ANASTASOPOULOS, ES PEISNER-FEINBERG \& MD POE. 2003. The comprehensive language approach to early literacy: the interrelationships among vocabulary, phonological sensitivity and print-knowledge amongst preschool-aged children. Journal of Educational Psychology, 95(3):465-481.

EWN. 2017. Reading results. Available from http://ewn.co.za/2017/12/05/78-of-grade-4pupils-in-sa-are-illiterate-study [Accessed: January 2018].

FLEISCH, B. 2008. Primary education in crisis: why South African schoolchildren underachieve in reading and maths. Cape Town: Juta.

GRAVEN, MH. 2013. Poverty, inequality and mathematics performance: the case of South Africa's post-apartheid context. ZDM. DOI: https://doi.org/10.1007/s11858-013-0566-7 Hardcopy 2014. 46 (7) pp 1039-1049

HLALELE, D. 2012. Social justice and rural education in South Africa. Perspectives in Education, 30(1):111-118.

JUSTICE, LM \& HK EZELL. 2001. Word and print awareness in 4-year-old children. Child Language Teaching and Therapy, 17(3):207-225.

KATIMS, DS. 1991. Emergent literacy in early childhood special education: curriculum and instruction. Topics in Early Childhood Special Education, 11(1):69-84.

KLEIN, M. 2006. Literacy and numeracy at the crossroads: a return to modernity or a futures orientation in preservice teacher education. ECLAS-II Literacy Development Checklist. (Available from CTB/McGraw-Hill).

KOTHARI, CR. 2004. Research methodology: methods and techniques. New Delhi: New Age International.

MCDONALD, D, P PROCTOR, W GILL, S HEAVENS, J MARR \& J YOUNG. 2015. Increasing early childhood educators' use of communication-facilitating and languagemodelling strategies: brief speech and language therapy training. Child Language Teaching and Therapy, 31(3):305-322.

MILLER, S \& L PENNYCUFF. 2008. The power of story: using storytelling to improve literacy learning. Journal of Cross-Disciplinary Perspectives in Education, 1(1):36-43.

MOONSAMY, S. 2015. Classroom-based speech-language services: collaborative practice between speech-language therapists and teachers. In S Moonsamy \& H Kathard (Eds), Speech-language therapy in a school context: principles and practices. Pretoria: Van Schaik.

MOONSAMY, S \& S CAROLUS. 2019. A model for emergent literacy support for children from marginalized populations. Folia Phoniatrica et Logopaedica, 71:83-93. DOI: https://doi.org/10.1159/000493893

MOONSAMY, S, A MUPAWOSE, J SEEDAT, M MOPHOSHO \& D PILLAY. 2017. Speech-language pathology and audiology in South Africa: reflections on transformation in professional training and practice since the end of apartheid. Perspectives of the ASHA Special Interest Groups SIG 17, 2(Part 1).

NEL, N, K MOHANGI, S KROG \& O STEPHENS. 2016. An overview of grade R literacy teaching and learning in inclusive classrooms in South Africa. Per Linguam, 32(2):4765. DOI: http://dx.doi.org/10.5785/32-2-651

OWENS, JR, RE. 2014. Language development: an introduction (8th ed.). USA: S.1. Pearson.

RHYNER, PM. 2009. Emergent literacy and language development: promoting learning in early childhood. New York: Guilford. 
SILVERMAN, D. 2011. Interpreting qualitative data: a guide to the principles of qualitative research. London: S.l: Sage.

SOUTHWOOD, F \& O VAN DULM. 2015. The challenge of linguistic and cultural diversity: does length of experience affect South African speech-language therapists' management of children with language impairment? South African Journal of Communication Disorders, 62(1):1-14.

TAYOB, F \& S MOONSAMY. 2018. Caregivers' reading practices to promote literacy in a South African children's home: experiences and perceptions. South African Journal of Communication Disorders, 65(1):559. DOI: https://doi.org/10.4102/sajcdv65i1.559

TAYLOR, LC, JD CLAYTON \& SJ ROWLEY. 2004. Academic socialization: understanding parental influences on children's school-related development in the early years. Review of General Psychology, 8(3):163-178.

TZURIEL, D. 2013. Mediated learning experience and cognitive modifiability. JCEP, 12(1):59-80.

VAN STADEN, S \& R BOSKER. 2014. Factors that affect South African reading literacy achievement: evidence from pre-PIRLS 2011. South African Journal of Education, 34(3):1-9.

WALTON, E, T BEKKER \& B THOMPSON. 2015. South Africa: the educational context. In S Moonsamy \& H Kathard (Eds), Speech-language therapy in a school context: principles and practices. Pretoria: Van Schaik.

\section{BIOGRAPHICAL NOTES}

Stephanie Carolus is a Speech Pathologist and Audiologist at a School for Learners with Severe Intellectual and Physical Disabilities. She is bilingual, English and Afrikaans speaker. She volunteers at NGOs and Edu care Centres. Stephanie's research interest includes literacy and language in children in underserved communities. She is currently registered for a Masters in Speech Pathology. Email: stephaniecarolus1@gmail.com

Sharon Moonsamy is an Associate Professor in Speech Pathology at the University of the Witwatersrand. Her research interests are cross disciplinary in the areas of cognition, metacognition, language, literacy and learning. Sharon belongs to local [SASLHA] and international Associations [IALP]. Her current projects relate to transformation of the curriculum in Higher Education. Email: Sharon.moonsamy@wits.ac.za 